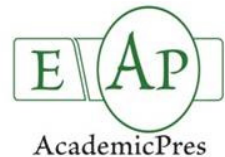

AcademicPres

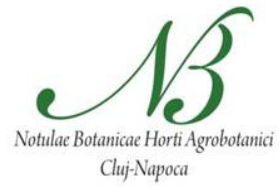

\title{
Public Perception of Forestry Practices in Malaysia
}

\author{
Jegatheswaran RATNASINGAM ${ }^{1 *}$, Cristina VACALIE ${ }^{2}$, \\ Adriana F. SESTRAS 3 , Florin IORAS ${ }^{4}$
}

\author{
${ }^{1}$ Universiti Putra Malaysia, Faculty of Forestry, 43400 UPM, Serdang, Selangor, Malaysia; jegaratnasingam@yahoo.com (*corresponding author) \\ ${ }^{2}$ Transilvania University of Braşov, Faculty of Silviculture and Forest Engineering, 1 Şirul Beethoven, 500123, Braşov, Romania; \\ cris_d84@yahoo.com \\ ${ }^{3}$ University of Agricultural Sciences and Veterinary Medicine, 3-5 Manastur Str., 400372, Cluj-Napoca, Romania; adriana.sestras@usamvcluj.ro \\ ${ }^{4}$ Buckinghamshire New University, Queen Alexandra Road, High Wycombe, Buckinghamshire HP 11 2JZ, United Kingdom; florin.ioras@googlemail.com
}

\begin{abstract}
This article endeavours to assess public perceptions about the importance of forests for young people in the age group of 21-35 years in Malaysia based on 1,503 reliably answered interviews. Overall patterns show that timber production and environment protection are very important attributes among this age group. The interviews indicated high awareness of negative environmental impacts of deforestation, with high levels of concern over higher temperatures, air pollution and loss of clean water sources. Large-scale deforestation (e.g., for industrial oil palm plantations) and political interference appeared to be more context-dependent, with most respondents considering it to have on overall negative impact on sustainable forestry in Malaysia. Increasing information accessibility, awareness and experience in the forest of the young people could ultimately result in positive processes.
\end{abstract}

Keywords: conservation, Malaysia, politics, tropical forest, young people perception

\section{Introduction}

Malaysia is recognized as a leader in tropical forest management, and the tropical rain forest in the country is regarded as one of the most complex ecosystem in the world (Whitmore, 1984; Manokaran, 1992). The forest management practices in the country have been credited to the British colonial masters in the late 1800 s, whose focus was on timber extraction mainly for ship building and construction of railways (Kumari, 1996; Ratnasingam and Ioras, 2006). During the colonial period, the forest management system evolved through the Gutta Percha era (1900-1910) and the Improvement and Regeneration Felling era (1911-1942), without much concern for the environment (Attah et al., 2010; Ratnasingam and Ioras, 2006; Ratnasingam et al., 2008). Even during the Japanese reign of the country, forestry matters remained the same (Thang, 1987).

As a consequence of the loss of forests during the $2^{\text {nd }}$ World War, the Malayan Uniform System (MUS) was implemented to manage the forest due to the high demand for wood raw materials in the country and internationally. However, MUS system characteristically paid little attention to environmental matters, and was thus considered unsuccessful as a forest management system. Problems associated with the MUS system were the uneven stocking of timber species on difficult terrain, lack of natural regeneration on the forest floor before logging, uncertain seedling regeneration after logging due to irregular flowering and soil erosion on the hilly Dipterocarp forest. Due to an increasing appetite for timber resources, especially in the booming timber processing industries, it became apparent that a new forest management system was needed to ensure sustainability of the forest resources in the future (Ratnasingam and Ioras, 2006).

Inevitably, a new forest management system known as the Selective Management System (SMS) was introduced to address the shortcomings of the MUS system and to ensure that the forest resource in the country is managed sustainably. The system has the advantage that it gives forest managers the flexibility to choose the minimum diameter of stems they wish to exploit. However, it is less reliable than the Malaysian Uniform System and marks a drastic departure from the uniform, monocyclic felling system to a much more complex polycyclic system. Also, the more frequent harvesting may cause substantial damage to the remaining forest and the system requires a strong capacity to monitor and control harvesting. Empirical evidence of the sustainability of this system is also lacking, because large areas managed under this system have yet to be harvested for a second time (Mok, 1992).

Experience with these forest management systems in Malaysia suggests that they were complex to organize and monitor. They also require sophisticated technical capacity that often is not available on the ground. Because of these obstacles, experience with these systems is insufficient to 


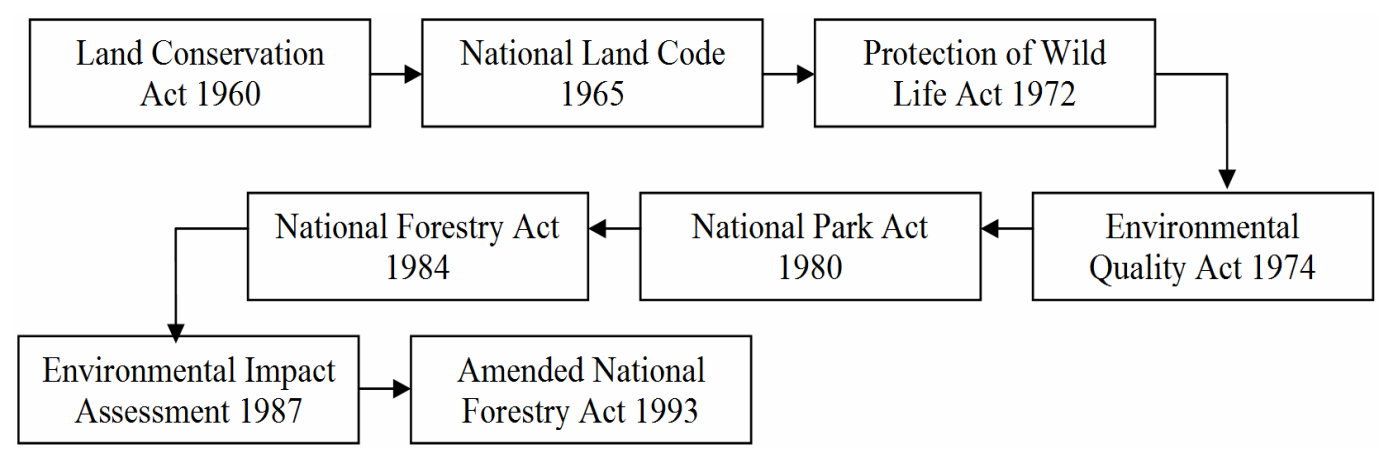

Fig. 1. Evolution of Forest Policy in Malaysia

prove their feasibility although their failure was not caused by the lack of technical knowledge (Ratnasingam and Ioras, 2006). The era towards environmentalism (1970-1980) followed by the focus on biodiversity (1981-1990) and the ensuing policies of forest resources which took a central role from 1991 to 2000, were testing times for the forest management system in Malaysia. Although the forest resource was sustainably managed, it failed to meet the demand for wood resources from the booming wood processing sector, which resulted in increased importation of wood materials from neighbouring countries and the increased reliance on plantation wood resources, particularly Rubberwood (Hevea brasiliensis) (Ratnasingam and Ioras, 2006).

Inevitably, the forest resource in the country was increasingly under pressure to cope with multiple demands not only from the socio-economic but also the environmental and recreational perspectives. In this context, the management of the forest for multiple-purposes was expected to be laid out in the country's prevailing forest policy and management.

\section{Evolution of Forest Policy in Malaysia}

Forestry in contemporary Malaysia continues to be dominated by the legacy of Federal-State relations, a pattern initiated during the colonial era (Ratnasingam and Ioras, 2006). State control over land, a potent source of political power, undermines the federal government's role for policy and technical management. The absence of federal control over land, coupled with the country's desire for rapid development, spurred unbridled land concession for logging and agricultural conversion. Politics, crony capitalism and flawed policies relating to the timber industry, widened the gap between forest depletion and regeneration. As lowland forests shrank and logging moved into the hills, foresters sought appropriate adaptations in harvesting regimes and techniques, but the speed of land conversion, encouraged by the spectacular expansion of the wood-based industry entrenched in vested political interests, compromised the regulatory safeguards needed for minimizing forest cover loss (Aiken and Moss, 1975; Goh, 1982).

The 1978 National Forest Policy and the 1984 National Forestry Act came too late in the day and left the National Land Council without the necessary power to regulate land
Tab. 1. Conversion of Forested Land* for Other Purposes in Malaysia (million hectares)

\begin{tabular}{cccc}
\hline Year & Forested area & Tree crop land & Non-forested area \\
\hline 2000 & 20.20 & 4.8 & 8.0 \\
2005 & 19.49 & 4.8 & 8.7 \\
2006 & 19.49 & 4.8 & 8.7 \\
2007 & 19.47 & 4.8 & 8.7 \\
2008 & 18.08 & 5.9 & 9.1 \\
2009 & 18.03 & 5.9 & 9.1 \\
2010 & 17.99 & 5.9 & 9.0 \\
2011 & 17.98 & 6.2 & 8.9 \\
\hline
\end{tabular}

${ }^{*}$ Note: Agricultural land included oil palm, rubber, cocoa and coconut plantation only; non-forested area include agriculture, housing, construction and industrial area

clearance in accordance with actual agricultural needs (Johns, 1997). The approach of the Malaysian National Forestry Council (NFC) towards forestry is somewhat contradictory. On one hand, the NFC refers to the multifunctional roles of the forests, i.e. they not only supply timber and non-timber products, but also play an important role in hydrology, support communities and possess both recreational and research potential. On the other hand, it advocates sustainable forestry practices, defined solely in terms of the ability to ensure continued supply of timber. Inevitably, holistic forest management was impeded in the country, despite the evolving forest policies with very noble objectives (Fig. 1).

The poor coordination between agencies and the prevailing vested interest within the forest sector resulted in a sharp decline in total forest cover in the country since independence (Tab. 1).

Malaysia's substantially reduced forest capital, the uncertainties of sustainable logging and the changing values and expectations among its citizens point to a return to the non-timber value of forests (Sayer, 1986). Forest botany has entered a new phase of exploration for genetic resources encouraged by the incentives for biodiversity conservation. Further, the collection of medicinal plants and other nontimber forest products (NTFPs) to meet rising demands offer improved opportunities for making the best use of the forest resource in the country. On hindsight, where socio-political and constitutional constraints have emasculated forestry's influence on development, civil society's stewardship offers the best chance to undo the trend in forest management left 
282

behind by the legacy of the colonialists in the country (Ratnasingam, 2001). Against this background, forest management principles built on strong scientific foundation was no longer an option, but a necessity to ensure that policymakers are advised accordingly to make sound decisions that would not jeopardise the sustainability of the country's forest resource.

\section{Forestry Research and Development}

The real problem at the interface between forestry research and application is that research is rarely able to provide support in the form of a continuous stream of confidence-building discoveries ( $\mathrm{Ng}, 1996$; Abdul Razak et al., 2007). Forest research was so slow to produce useful results that some years there was almost nothing of importance to report. It is troubling to note that research is being promoted in developing countries on the premise that research is an efficient problem-solving mechanism that countries cannot afford to neglect.

Previous experiences have shown that research and development in forestry in Malaysia has had limited success (Ng, 1996). In 1965, the UNDP stepped in with a pilot project to establish pine plantations for pulp and paper production. However, with small growth rates the project was terminated inconclusively in the late 1970s, in spite of 15 years of international and national research effort. The pine fiasco was followed by an even larger plantation project based on Acacia mangium and backed by a loan from the Asian Development Bank (ADB), and after 15 years of effort, the Acacia planting program had serious problem with the high incidence of heartrot in the stems. In the natural forests, enrichment planting was promoted through the 1960s and 1970s and backed up by a Japanese research team in addition to considerable local effort. Yet enrichment planting was given up in about 1980 due to the excessive cost and the Forestry Department implemented the compensatory forest plantations to supplement the slowgrowth of the natural forest to ensure sufficient timber supply for the country.

In many developing countries, forestry research is undertaken by newly-recruited scientists with enthusiasm but the majority fails to find inspiration and motivation, and soon settled into a dull routine. They failed to find the path of discovery which alone can bring life into research. In fact, all successful scientists know that discovery is an art, but scientists get little or no training in this art. Instead, they get trained in 'research methodology' which is only remotely related to the art of discovery $(\mathrm{Ng}, 1996)$.

In going through the history of discovery in forestry in Malaysia, it is evident that discoveries are made in many different ways, e.g., by questioning (the pine seed production breakthrough), screening (the discovery that Shorea roxburghii is suited for bare-root planting), comparative experimentation (the discovery that under-storey control is more effective than over-storey control in stimulating regeneration), noncomparative experimentation (the confirmation of Acacia mangium as a miracle tree in a half-acre unreplicated trial), observations on single specimens (shoot regeneration from the woody core of a stump of Cochleospermum), observations on diverse specimens but not all at the same time (the dimorphic nature of the Dipterocarp shoot system), by analogy (deducing the nature of mangium wood by analogy with other woods) and, most importantly, by chance.

Against this background, it is apparent that the whole gambit of forestry research and development is driven by the perception that scientifically-oriented research activities would provide the necessary solutions to the challenges and problems faced by the forestry sector. In reality however, the impact of forestry research and development towards the management of the forest resource is the country remains obscure (Aiken and Leigh, 1988; Ratnasingam and Ioras, 2006). Therefore, the objective of this study is to evaluate the public perception of forestry practices and the value of the forest in Malaysia, which will provide the necessary information to gauge social acceptability of the forestry sector.

Forests are an integral part of the nation and its economy. Among those interested in the long-term viability of the forest resource are young people, specifically those in the age group of 21-35 years. Indeed, their beliefs and attitudes play an important role in determining how they perceive the forests should be managed and ultimately, in how they are sustained for future enjoyment and economic returns (Hezri and Hasan, 2006). Within this context, this research aims to develop an in-depth understanding of perceptions, beliefs and behaviors of people towards the forest in Malaysia.

\section{Material and method}

An interview survey of young people (in the age group of 20-35 years) living in the Kelang Valley in Malaysia was conducted in September to December 2013, which covered a total of 1503 respondents. The respondents were randomly approached and agreed to be interviewed using a structured questionnaire that was previously pre-tested among 25 respondents for its effectiveness. The questionnaire had four parts, i.e. Part I covered the general perception about the forest, Part II examined the relative importance of the forest, Part III evaluated the respondents knowledge on the roles played by the forest and Part IV examined the effectiveness of forest management from the public's perspective. A total of 4200 respondents were initially approached, giving a response rate of $35 \%$. Respondents were older (63\% more than 30 years old), largely male (74\%) and well educated (69\% were degree holders). The respondents were mostly residing in the Kelang Valley (96\%). The collated data was tabulated and analyzed using the t-test and factor analysis to establish the key public perception of the forest and its importance.

\section{Results and discussion}

When asked about the general perception of the forest, $73 \%$ of the respondents regarded the forest as a timber producing entity (Tab. 2). Further, $92 \%$ of the respondents have not had any experience walking through a forest over the last three years. All the respondents were also asked what were the top three concerns about the forest in the country, and the top three responses include: (i) shrinking resource, (ii) impaired air quality and (iii) climate change. The response to these questions reveal that the respondents were concerned about two issues: the depleting forest cover and its negative impact on the environment.

The next series of questions examined the relative importance of the forest to the public. Most respondents 
(77\%) thought that the forest was solely for the economic extraction of forest products, especially timber. Only $14 \%$ of the respondents thought that the forest served recreational and environmental purposes.

A high proportion of the respondents (63\%) perceived the need to conserve the forest, although only $37 \%$ of the respondents responded as having sufficient knowledge about the forest and the roles played by the forest. Further, 69\% of the respondents were not aware that the field of forestry and a career in professional forestry is possible.

In the final set of questions, $81 \%$ of the respondents were of the opinion that the forest resource in the country was not well managed. Among the top three challenges to the sustainability of the forest are: (i) political interference, (ii) agriculture conversion and (iii) logging. In fact, only $16 \%$ of the respondents thought that the forest resource in the country was managed scientifically and is supported by sound research practices.

In order to evaluate the main factors that governed the prevailing public perception of the forestry sector in Malaysia, these questions were transformed into attributes that form perception as reported by McCool et al. (1986). The transformation and the factor analysis conducted revealed that perception of the forestry sector in Malaysia is governed by (1) lack of information, (2) lack of experience, (3) low interest in the environment and nature, (4) cultural

Tab. 2. Public Perception of the Forestry Sector in Malaysia

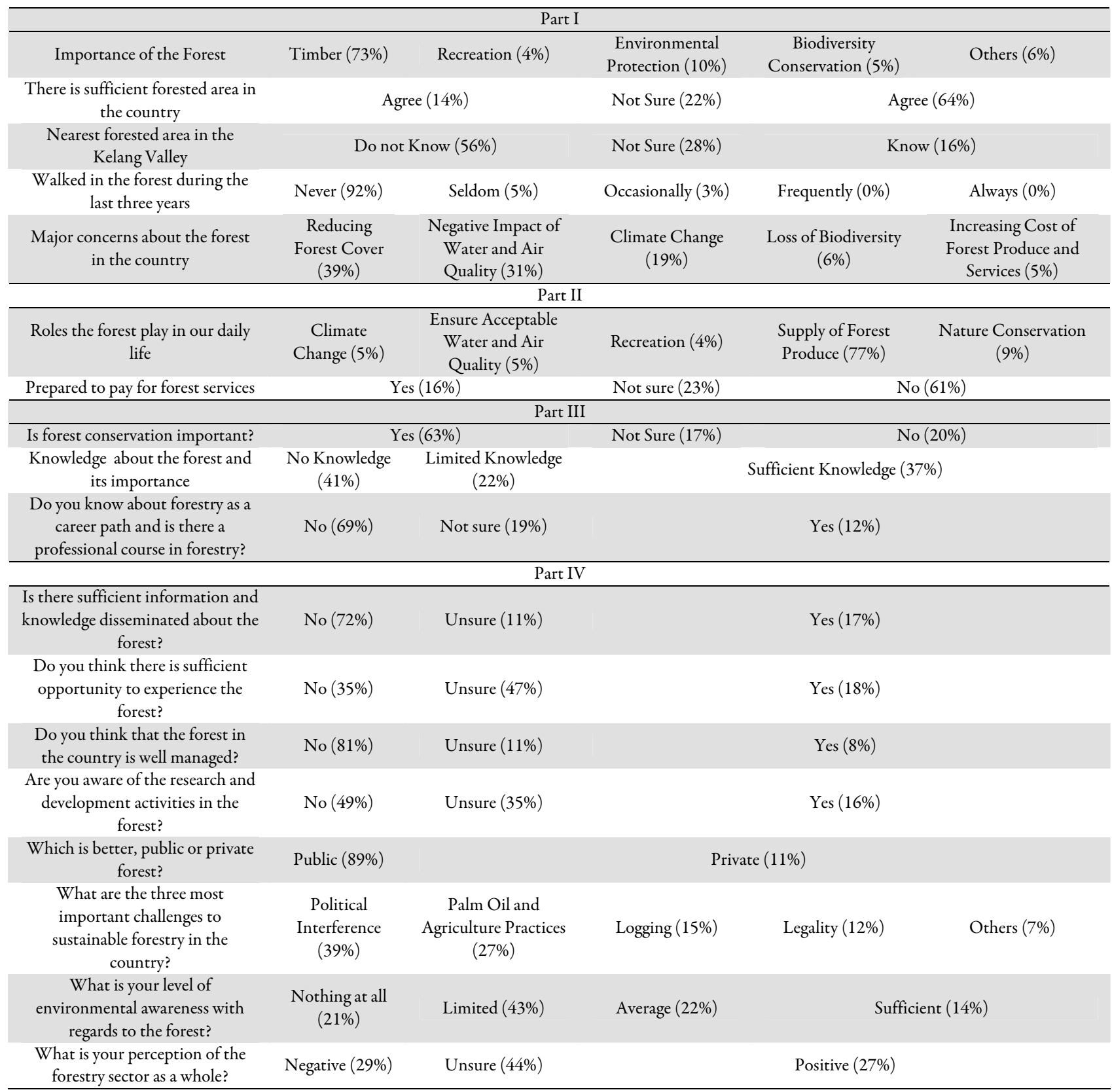


284

characteristics and (5) rapid development and urbanization. This finding clearly shows that the awareness of the forest and the forestry sector is poor among the general public in Malaysia, and in order to change perception and attitude towards the forestry sector improved information dissemination and experience sharing should be promoted.

Information and experience are important factors for creating awareness, which in the case of forestry appears to be lacking. As reported by Tindall (2003) it is important to tailor information to the audience being addressed. As some of the studies examining the views of different groups suggests, the target audience for information does matter (Zhi and Bengston, 1997). It must be emphasized that "disinterested public" is more likely to make more affective judgments (i.e., based on emotional reactions to the aesthetics) in terms of forest management practices such as clear-cutting and illegal logging, the "interested public" tends to "evaluate forest practices more cognitively" and thus possibly be more receptive to new information and consider the practices in light of other values important to them (Tindall, 2003).

When it comes to the forestry issues, knowledge of the factors that influence perceptions and social acceptability will help in designing strategies to gain public support in favor of managing forest resources for multiple-purposes (Ratnasingam, 2001). Among the important points on social acceptability of the forestry sector that must be taken into account are:

1. Acceptability is a relative condition, and people must have clear alternatives to compare.

2. Acceptability is based on individuals' perceptions, which are influenced by science, experience, knowledge, ethical concerns, values, attitudes, beliefs, and an individual's history with the landscape.

3. Acceptability judgments are influenced by both social and geographical context.

4. There is often a gray area between practices and conditions people judge "acceptable" and "unacceptable."

This study reveals that members of the public need to have a clear understanding of the forest resources and its management purposes, in order to make acceptable judgments, and may not be inspired to act on behalf of a given alternative (such as willingness-to-pay for recreational services) unless they strongly feel it is more acceptable than another. Information plays a complex role in influencing perceptions of natural resource issues, with its impact affected by factors such as credibility, timing, and the link between scientific and other forms of knowledge (McCool et al., 1986).

Having increased knowledge about forest management may influence people's perceptions in different ways, as illustrated by the Nijnik (2004) study in which students and professionals reacted differently to the same information. Taking this and the important role of "reference" groups in shaping individuals' opinions into account means that messages about forests and its importance and management should be carefully crafted for specific audiences or even the general public as eluded by Ratnasingam and Ioras (2006).

When does perception lead to action? Given alternatives, people will make judgments about which one is acceptable, and if the existing condition is not sufficient, the individual will initiate behaviour, often within a group (Storch, 2011). Acceptability may not be directly observable, but "must be inferred from the absence of overt behaviour indicating a failure to achieve it" (Nijnik, 2004).

This link between perception and behaviour points to two important sides of social acceptability. On one hand, a more passive general public support in favor of certain policies and actions can produce "social legitimacy" or "social license," where the daily actions of companies, agencies, and organizations are seen as "desirable, proper, or appropriate within some socially constructed system of norms, values, beliefs, and definitions" (Tindall, 2003). One example is forest certification, where forestry practices must meet certain ecological criteria and standards of public acceptability, and in exchange are granted a "sustainable" label indicating to the public that the practices are acceptable or desirable. Perceptions and the resulting acceptability judgments are important in both cases, but the work required to create "support" or "legitimacy" vs. "action" may be significantly different.

This study reveals that for the forestry sector in Malaysia, it will be important to consider in which cases public support or legitimacy is sufficient and in which cases a greater degree of public involvement is needed, and work to influence perceptions and engage the public accordingly. Increased provision of information, knowledge and experience to the general public about the forest would also go a long way towards shaping the social acceptability of the forestry sector in the country.

\section{Conclusions}

Despite having a large forest and forest industries, the general public in Malaysia lack awareness and knowledge about the forestry sector. Inevitably, the forestry sector is perceived to be unsustainable and will impair the future well-being of the society at large with negative implications on the environment and climate. In this context, it is apparent that this preconception could be undone by increasing information accessibility, awareness and experience within the forest for the general public.

The results of this study shed some interesting new light on various parts of young people perception regarding Malaysian forests and forestry. While the outcomes showed some useful overall trends in public perception, the study also pointed out key shortcomings of current forest communication in Malaysia and provided key areas for improvement, e.g., forest services, environmental awareness, forest role in day to day activity in society. Finally, the survey serves as a valuable tool for future follow-up on other age groups of Malaysian society.

\section{References}

Abdul Razak MA, Norini H, Lim, HF (2007). The Role of Forestry Research and Development (R\&D) Institution in Policy Formulation and Implementation: A Malaysian Perspective. Pertanika Journal Tropical Agricultural Science 30(2):153-163. 
Aiken SR, Leigh CH (1988). Environment and the Federal Government in Malaysia. Applied Geography 8:291-314.

Aiken SR, Moss MR (1975). Man's Impact on the Tropical Rainforest of Peninsular Malaysia: A Review. Biological Conservation 8(3):213-229.

Attah A, Ioras F, Abrudan IV, Ratnasingam J (2009). The Voluntary Partnership Agreement: The Ghanaian and Malaysian experiences. International Forestry Review 11(3):311-318.

Goh KC (1982). Environmental Impact of economic development in Peninsular Malaysia: A Review. Applied Geography 2:3-16.

Hezri AA, Hasan MH (2006). Towards Sustainable Development? The Evolution of Environmental Policy in Malaysia. Natural Resources Forum 30(1):37-50.

Johns AD (1997). Timber Production and Biodiversity Conservation in the Tropical Rain Forests. Cambridge, Cambridge University Press.

Kumari K. (1996). Sustainable Forest Management: Myth or Reality? Exploring the Prospects for Malaysia. Ambio 25(7):459-467.

Manokaran N (1992). An Overview of Biodiversity in Malaysia. Journal of Tropical Forest Science 5(2):271-290.

McCool SF, Benson RE, Ashor JL (1986). How the Public Perceives the Visual Effects of Timber Harvesting: An Evaluation of Interest Group Preferences. Environmental Management 10(3):385-391.

Mok ST (1992). Potential for Sustainable Forest Management in Malaysia. Unasylva 189(43):28-33.

Nijnik M (2004). To An Economist's Perception on Sustainability in Forestry-in-Transition. Forestry Policy and Economics 6(3/4):403-413.
Ng FSP (1996). High Quality Planting Stock - has research made a difference? CIFOR Occasional Paper No. 8, Bogor, Indonesia.

Ratnasingam J (2001). National Vision for the Malaysian Foresty Sector - A Perspective. Asia Link Timber: Premier Issue: 1214.

Ratnasingam J, Ioras F (2006). Colonial British Forestry in Malaysia and the Years Thereafter. Colorcom Grafik Sistem Sdn. Bhd., Malaysia.

Ratnasingam J, Macpherson TH, Ioras F, Abrudan IV (2008). Chain of Custody Certification among Malaysian wooden furniture manufacturers: status and challenges. International Forestry Review 10(1):23-28.

Sayer JA (1986). Tropical Forest Action Plan. Committee on Forest Development in the Tropics, Rome, FAO.

Storch S (2011). Forestry Professionalism Overrides Gender: A Case Study of Nature Perception in Germany. Forest Policy and Economics 13(3):171-175.

Tindall DB (2003). Social Values and the Contingent Nature of Public Opinion and Attitudes about Forests. The Forestry Chronicle 79(3):692-705.

Thang HC (1987). Forest Management Systems for Tropical High Forest, with Special Reference to Peninsular Malaysia. Forest Ecology and Management 21:3-20.

Whitmore TC (1984). Tropical Rain Forest of the Far East. Oxford University Press.

Zhi X, Bengston DN (1997). Trends in National Forest Values among Forestry Professionals, Environmentalists, and the News media, 1982-1993. Society and Natural Resources: An International Journal 10(1):43-59. 